\title{
BULKHEAD DOOR - CRITICAL EVACUATION STATES
}

\author{
Józef Flizikowski ${ }^{1)}$ \\ Weronika Kruszelnicka ${ }^{1)}$ \\ Mirosław Michałowski ${ }^{2)}$ \\ Grzegorz Szala ${ }^{1)}$ \\ Andrzej Tomporowski ${ }^{1)}$ \\ 1) UTP University of Science and Technology in Bydgoszcz, \\ Faculty of Mechanical Engineering, Poland \\ ${ }^{2)}$ Remontowa Hydraulic Systems, Sp. z o.o. Gdansk, Poland
}

\begin{abstract}
The article is a preliminary to a modification concept of the sliding watertight bulkhead door used on ships and vessels. Hydraulic or electro-hydraulic drives used to move these doors require complicated and extended pressure installations with large amounts of hydraulic fluid. Well-known operational drawbacks of these installations include high level of noise and possibility of various leaks in the hydraulic system. Being the first in a series, the present article describes and analyses critical states which can take place during evacuation of people through openings in the watertight bulkhead doors on seagoing ships and vessels.
\end{abstract}

Keywords: sliding watertight bulkhead door, evacuation of individuals, safety, modelling of elements and relationship of evacuation

\section{REGISTER'S REQUIREMENTS AND TECHNICAL CHARACTERISTICS CONCERNING BULKHEAD DOORS}

Register's requirements [11]: Each power-operated sliding watertight bulkhead door: shall have a vertical or horizontal motion and shall be normally limited to a maximum clear passage width of $1,2 \mathrm{~m}$. The Administration of the flag State may allow a wider door, but only to the dimension considered necessary for proper operation of the ship, provided that other safety measures, including those below listed, are taken into account. In particular, special consideration shall be given to the strength of the door and its closing devices to prevent leakages. The door shall be situated beyond the damage zone $\mathrm{B} / 5$. It shall be kept closed when the ship is at sea, except for limited periods established by the Administration of the flag State as absolutely necessary. The door shall be fitted with necessary equipment to open and close it using electric or hydraulic power, or any other form of energy considered acceptable by the Administration of the flag State. Moreover, the door shall also be provided with an individual handoperated opening and closing mechanism. It shall be possible to open and close the door by hand at the door itself from either side, and, additionally, to close it from an accessible place above the bulkhead deck using an all-round crank motion or some other movement providing the same degree of safety approved by the Administration of the flag State. The direction of rotation or other movement of the controller is to be clearly indicated on all operating positions. The time needed to close the door completely using the hand-operated system shall not exceed $90 \mathrm{sec}$ when the ship is in upright position. The door shall be provided with controllers for power-operated opening and closing from both sides, and for closing it from the central operating console at the navigating bridge $[3,4,12,14]$.

Technical characteristics assume that: the watertight bulkhead door meets the requirements of the SOLAS Convention and those of Classification Societies and Institutions. The regulations and approval of the Classification Societies are agreed with the producer. The door structure is made of steel and welded. The door is installed by direct welding of its frame into the watertight bulkhead. The direction of motion of the door slider is horizontal. The closing direction is defined when looking at the watertight door from 
the drive unit side (Fig.1). The permissible load capacity of the door is determined by the buyer when ordering. It is expressed as the maximal water head which can load the door $[2,3,5$, $6,10]$. This water head is measured from the lower edge of the door to the lower bulkhead deck surface in the centre plane of the ship. The electro-hydraulic or electric drive is installed on the door [11].

Use: The watertight door is used for watertight blockage of communication passages in watertight bulkheads on seagoing passenger and cargo ships, yachts, and drilling platforms.

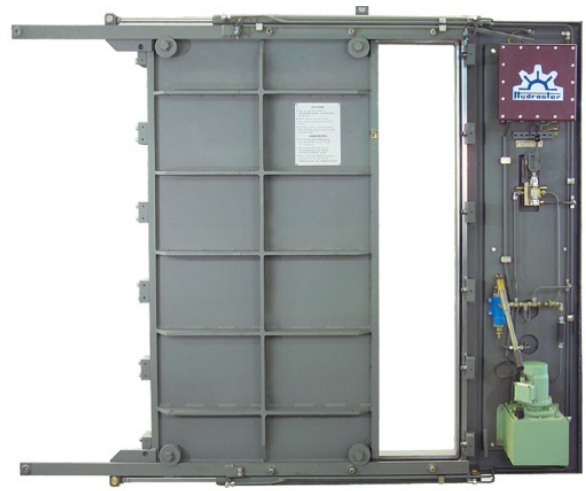

Fig.1. View of the bulkhead door being the object of critical evacuation state analysis [Remontowa Hydraulic Systems Sp. z o.o. Gdansk]

The reported research aimed at describing and analysing critical states occurring when closing a single door opening, or a sequence of door openings. The goal of the research has been reached via analyses and assessments of models of probable states/relations between door openings and individuals.

\section{MODEL OF EVACUATION ELEMENTS AND RELATIONS}

It was assumed for the purpose of the present analysis that the initial model of an individual passing through the opening is the $1 \mathrm{D}$ individual, and that the individuals are always configured with their longer axes perpendicular to the direction of motion of the door.

The state of individuals is described by the probability distribution of shape features (overall dimensions) of the evacuated people $[3,9,15]$. Since the individual in the door is subject to the same danger process in each door opening, the state is indexed by the number of doors in particular bulkheads along the evacuation route $(n)$ and the number of danger $(m)$ :

$$
\rho_{n}^{m}:\left(0, l_{\max }\right] \rightarrow[0,1], \int_{0}^{l_{\max }} \rho_{n}^{m} d l=1 .
$$

where:

$\rho_{n}^{m}$ - probability distribution of shape features,

$l_{\max }$ - maximal shape dimension of the evacuated individual.

Since moving to the next door involves passing through the danger process, $n \leq m$, then the safety state in the first door opening before the first danger is $\rho_{0}^{0}$ and is the initial state. Hence, it can be described using a function concentrated around $l_{\text {max }}$.

Safety state changes depend on two mechanisms, which are: closing the analysed space, and removing individuals of given size from it. Ultimately, the model of individuals should take into account three degrees of freedom of their position and motion with respect to the door opening. In the examined case, the space occupied by the same number of individuals can vary depending on their size and shape distributions.

A basic goal of modelling was to obtain a mathematical relation providing an answer to the problem question about filling of the door opening, i.e. how particular factors, such as design and performance features for instance, affect the dynamics of door passing by individuals, and what is the capacity of evacuation of individuals, for the watertight bulkhead door structure produced by the Remontowa Hydraulic Systems, Sp z o.o. [4] selected as an example. Additionally, the research was expected to bring more details on the complexity of phenomena, processes, and relations observed during emergency evacuation of individuals in multi-bulkhead and multi-door variants.

Passage conditions: The motion of individuals through the bulkhead door opening is uneven, due to design properties of the structure and individual features, including danger. It starts when the surface of the sliding door does not coincide with the surface of the bulkhead door opening. Then, the cross-section of the door opening becomes smaller due to sliding motion of the door, until the opening is completely closed. When the door surface closes effectively the opening cross-section, the passage process ends. For the purpose of the present analysis the following simplifications were adopted:

1) the door opening cross-section is a convex [8, 13],

2) the volume of the opening is a cuboid (Cartesian product of opening cross-section and door thickness),

3) at a given time, the opening can lead to only one opening in the adjacent door.

Moreover when calculating the evacuation capacity $V e$, the following parameters and symbols were adopted in mathematical considerations:

$$
V e=f\left(y_{n}, \tilde{y}_{n}^{(k)}, V_{n}^{m}\right)
$$

where:

Ve - evacuation capacity,

$y_{n} \quad$ - thickness of door $n$,

$\tilde{y}_{n}^{(k)}$ - minimal height (at door end) to which the individual fills the opening in the $n$-th door after $k$-th successful passage,

$V_{n}^{m}$ - volume of the individual in the $n$-th door opening after $m$-th passage.

To verify the adopted conditions in practice, the analysis was performed for a structure in which the doors in successive bulkheads labelled with even numbers have the velocity equal to $v_{0}=0$, while the doors with odd numbers have the identical linear velocity equal to $v_{1}$. 
Conditions for filling and passing capacity. The passing capacity of the door opening is schematically illustrated in Fig. 2.

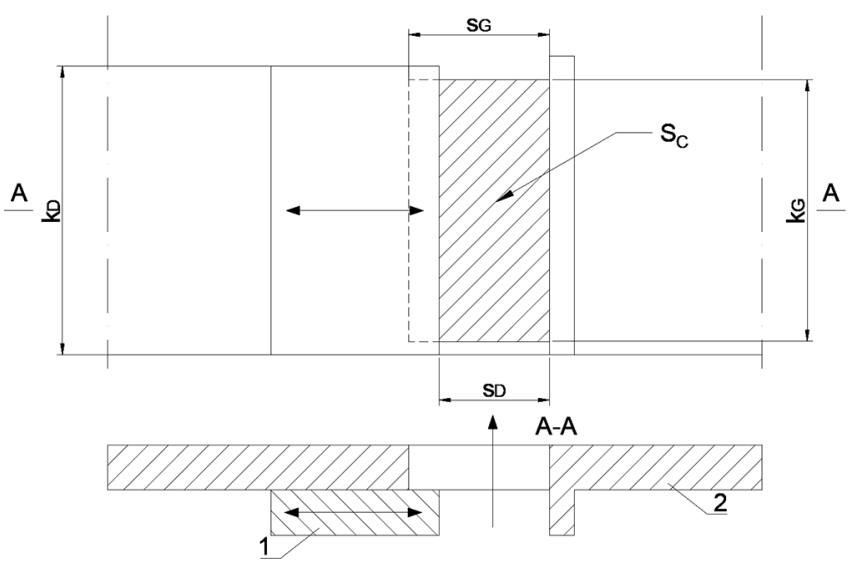

Fig. 2. Functional scheme of evacuation bulkhead door: 1 -sliding door, 2- bulkhead wall

When the intersection (common area Sc) of the opening in the bulkhead wall and door opening areas is maximal, its starts to decease. In a general case, the opening is fully opened and cannot be closed, as the entire intersection area can be filled with individuals. To determine the critical state of evacuation, a phase of relative motion of individuals is to be found for which the entire intersection of the door plate and opening areas is filled with individuals. Here, the following simplifications were adopted:

1. Each opening was unambiguously assigned its cross-section point, the geometrical centre for instance. Thus, phases of relative motion of the bulkhead door with respect to the opening in the bulkhead wall can be described by the linear distance $a$ between the geometrical centres of the door and the opening. Limits for the range of $a$ were marked $a_{p}, a_{k}$. Functions $(C W, D, G)$ were defined which, for the assumed $\Delta a$, return the intersections of the door/opening areas in the successive bulkhead walls, according to the evacuation direction. The symbol $a_{\max }$ represents the distance for which the function $|C W|$ reaches the maximum (if the function reaches more than one local maximum $a$, then $a_{\max }$ is the highest of them). A simplification was assumed that the acceleration components $\vec{g}_{D}, \vec{g}_{G}$ are parallel to each other (they only differ by value, as a result of door motion with respect to the opening). Symbols $\mathrm{V}^{\mathrm{G}}, \mathrm{V}^{\mathrm{D}}, \mathrm{S}^{\mathrm{G}}, \mathrm{S}^{\mathrm{D}}$ denote, respectively, the volumes of door and bulkhead wall openings, and their areas.

2. For the given vector $\vec{g} \in \mathbb{R}^{3}$, the plane $H_{\vec{g}}$ was established which is parallel to this vector and tangential to the boundary of the set $C W(a) \times\{0\}$. Two planes of this type can be found, one positioned below the set $C W(a) \times\{0\}$ and one above it (the existence of exactly two tangent planes results from the intersection of the cross-sections). For the purpose of the present analysis the plane was chosen which crosses the space of the door opening. It represents the area of the individual at the time when the closing begins.
The cuboid $G(a) \times\left[0, y_{n}\right] \subset \mathbb{R}^{3}$ was divided by the plane $H_{\vec{g}}$. The volume obtained below the plane was identified as

$$
V_{\vec{g}_{D}}^{D}(a)=\int_{D} \min \left\{y_{n}, H_{\vec{g}_{D}}\left(s_{D}\right)\right\} k_{D} \cdot t_{D} \cdot s_{D}
$$

where:

$V_{\vec{g}_{D}}^{D}$ - design volume of the door opening,

$y_{n}$ - thickness of the $n$-th door (opening),

$H_{\vec{g}}$ - plane of varying division of the door opening,

$s_{D} \quad$ - door opening width

$k_{D}$ - door opening height,

$t_{D}$ - door opening thickness.

In the relative motion phase, this function assigns the individual its volume remaining in the evacuation opening when the closing starts.

4. In the similar way the cuboid $D(\Delta \alpha) \times\left[-y_{n+1}, 0\right] \subset \mathbb{R}^{3}$ was divided by the plane $H_{\vec{g}}$. The volume obtained below the plane was identified as

$$
V_{\vec{g} G}^{G}(a) \int_{G} \min \left\{y_{n+1}, H_{\vec{g}_{G}}\left(s_{G}\right)+y_{n+1}\right\} k_{G} \cdot t_{G} \cdot s_{G}
$$

where:

$V_{\vec{g} G}^{G}(a)$ - design volume of the opening in the bulkhead wall

$H_{\vec{g}_{G}} \quad$ - division plane of the opening in the bulkhead wall,

$y_{n+1} \quad$ - thickness of the $n+1$-th opening (bulkhead wall)

$s_{G} \quad$ - width of the opening in the bulkhead wall,

$\boldsymbol{k}_{G} \quad$ - height of the opening in the bulkhead wall,

$\boldsymbol{t}_{G} \quad-$ thickness of the opening in the bulkhead wall.

In the relative motion phase, this function assigns the individual its volume remaining in the bulkhead wall when the closing starts.

The expression $\left(V_{\vec{g}_{D}}^{D}, V_{g_{G}}^{G}\right)(a)$, is a decreasing function within the range of $\alpha \in\left(a_{\max }, a_{k}\right)$. After its inversion, the phase of motion is obtained in its image at which the closing starts, for a given volume of individuals in both door openings.

$$
a_{c}(V)=\left(V_{\vec{g}_{D}}^{D}+V_{\vec{g} G}^{G}\right)^{-1}(V)
$$

where:

$a_{c}(V)$ - instantaneous horizontal dimension of bulkhead door opening,

$V \quad$ - door opening volume.

This function was extended to include the set $\left[0, V^{D}+V^{G}\right]$, by moving $a_{k}$ to the left and $a_{\max }$ to the right of the primary domain of the function.

When the closing begins, the area of the intersection for the given volume is:

$$
S_{c=}\left|\left(C w \cdot\left(V_{\vec{g}}^{D}+V_{\vec{g}}^{G}\right)^{-1}\right)\right|:\left|O, V^{D}+V^{G}\right| \rightarrow \mathbb{R}
$$

where:

$S_{c}$ - intersection area of the door opening and the bulkhead wall,

$V^{D}$ - maximal volume of the door opening,

$V^{G}$ - maximal volume of the bulkhead wall. 
This is an increasing function - for higher numbers of individuals in the door openings the danger of blocking (appearance of critical state) begins earlier, when the intersection area is relatively large.

The obtained function can be considered the function of four variables, which are: total volume of individuals in the openings, direction of the effective component, and values of the acceleration components in the adjacent door openings (if exist) $S_{c}:\left[0, V^{D}+V^{G}\right] \times S^{1} \times \mathbb{R}_{+} \times \mathbb{R}_{+} \rightarrow \mathbb{R}$. This function is to be determined numerically and interpreted as the representation of the coded effect of shapes of openings on the evacuation process for different directions of effective evacuation acceleration vectors.

\section{MODEL DISCUSSION}

It was assumed that the density of distribution of individuals in the evacuation openings is known for the given door mechanism (object) and does not depend on the distribution of overall dimensions of the individuals moving through the bulkhead door opening, and that the evacuation is only executed in the direction perpendicular to the bulkhead surface. After passing through the door opening in a bulkhead on the evacuation route (Fig.3), the intersection of the evacuation cross-sections decreases and the closing process starts. For safety reasons it was assumed that none of the individuals passing through the opening becomes jammed. When analysing possible evacuation variants it was also assumed that the positions of individuals with respect to the plane on which the door is sealed is random with uniform distribution.

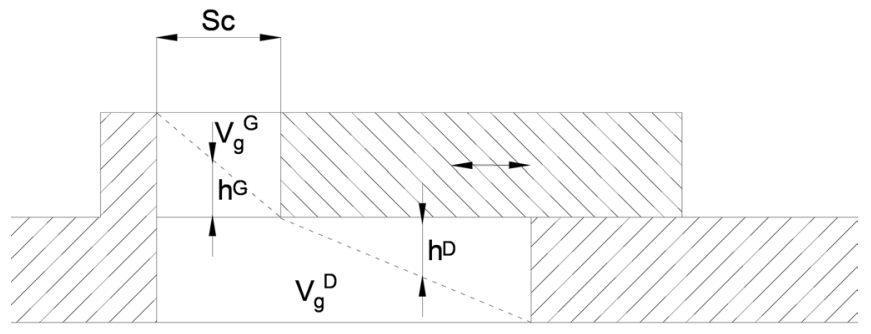

Fig. 3. Scheme of filling of the bulkhead/door unit

The danger always occurs in the space of the door opening and in the intersection area $S_{c}=S_{c}\left(V_{n}^{m}+V_{n+1}^{m}\right)$. Thus the critical distance in front of the closing plane is:

$$
h^{D}=\int_{w\left(\alpha_{c}\right)} \min \left\{y_{n}, H_{\vec{g}_{D}}\left(s_{D}\right)\right\} k_{D} \cdot t_{D} \cdot s_{D}
$$

$h^{D}$ - design thickness of bulkhead door.

While behind the closing plane:

$$
h^{G}=\int_{w\left(\alpha_{c}\right)} \min \left\{y_{n+1},-H_{\vec{g}_{G}}\left(s_{G}\right)\right\} k_{G} \cdot t_{G} \cdot s_{G}
$$

$h^{G}$ - design thickness of bulkhead wall.
The probability that, after closing, the individual appears on the other side of the bulkhead, in the volume behind the division plane $(x, x+d x)$ is:

$$
\rho_{n}^{m} d x-\rho_{n}^{m} \frac{x}{h^{D}}+\int_{l_{\min }}^{l_{\max }} \frac{l}{h_{D}} \frac{d x}{l} \rho(l) d l
$$

where: $x, x+d x-$ crosswise shape dimension limits of the passing individuals.

The first term represents the probability before closing. It should be decreased by the probability that the individual of size $x$ appears in the closing area. This probability is expresses by the product of the probability of appearance of the individual of size $x$ and the ratio $x / h^{D}$ (the individual has to get within the range $\left.(0, x) \subset\left(0, h^{D}\right)\right)$. The third term is the probability, integrated from $x$ to $l_{\text {max }}$, that the individual of size $l(\rho(l) d l)$ appears in the closing plane $l / h^{D}$.

After adopting the above assumptions, the distribution of sizes (overall dimensions) of individuals which appear in the space in front of the $(n+1)$-th bulkhead door, changes in the following way:

$$
\tilde{\rho}_{n+1}^{m}(x)=A_{n, m} \rho_{n}^{m}=\left(1-\frac{x}{h^{D}}\right) \rho_{n}^{m}(x)+\frac{1}{h^{D}} \int_{x}^{l_{\max }} \rho_{n}^{m}(l) d l
$$

$A_{n, m}-$ stochastic operator of the equation.

In the same way, the distribution of sizes (overall dimensions) of individuals which appear in the space behind the bulkhead door is:

$$
\tilde{\rho}_{n}^{m+1}(x)=\tilde{B}_{n, m} \rho_{n}^{m}=\left(1-\frac{x}{h^{D}}\right) \rho_{n}^{m}(x)+\frac{1}{h^{G}} \int_{x}^{l_{\max }} \rho_{n}(l) d l
$$

$\tilde{B}_{n, m}-$ stochastic operator of the equation.

It is noteworthy that the volume of individuals which are subject to passing is, in general, integer. The volume of individuals which passed to the next space is $S_{c} x h^{D}$, while the volume of the entire group of individuals which crossed the bulkhead door opening is: $V_{\vec{g}}^{D}\left(\alpha_{c}\right)-V_{n}^{m}$

That means that the second and third term in (11) are to be multiplied by the ratio of these volumes:

$\tilde{\rho}_{n}^{m+1}(x)=\tilde{B}_{n, m} \rho_{n}^{m}=\left(1-\frac{s c \cdot x}{V_{\vec{g}}^{D}\left(\alpha_{c}\right)-V_{n+1}^{m}}\right) \rho_{n}^{m}(x)+\frac{s c}{V_{\vec{g}}^{D}\left(\alpha_{c}\right)-V_{n+1}^{m}} \int_{x}^{l_{\max }} \rho_{n}(l) d l$

The obtained functions are nonnegative, as the sums of two nonnegative components. By integrating them from 0 to $l$ we can easily check that they have the form of probability distributions:

$$
\begin{aligned}
\int_{0}^{l_{\max }} \tilde{\rho}_{n+1}^{m}(x) d x & =1-\frac{\tilde{x}}{h^{G}}+\frac{1}{h^{G}} \int_{o}^{l_{\max }} \int_{o}^{l_{\max }} \rho_{n}(l) d l d x=1-\frac{\tilde{x}}{h^{G}} \\
+ & \frac{1}{h^{G}} \int^{L_{\max }} \int \rho_{n}(l) d x d l=1-\frac{\tilde{x}}{h^{G}}+\frac{1}{h^{G}} \int^{l_{\max }} x \rho_{n}(l) d x=1
\end{aligned}
$$

and identically for the distribution $\tilde{\rho}_{n+1}^{m}$. Hence the operators $A_{n, m}$ and $\tilde{B}_{n, m}$ are correctly defined stochastic operators. 
Assuming, for simplification purposes, that after closing the door the distribution behind the $(n+1)$-th opening is uniform, it is expressed by the weighted average of $\mathrm{z} \rho_{n+1}^{m-1}$ and $\tilde{\rho}_{n+1}^{m-1}$.

$$
\rho_{n+1}^{m}(x)=\frac{V_{n+1}^{m}}{V^{D}} \rho_{n+1}^{m-1}+\frac{V^{D}-V_{n+1}^{m}}{V^{D}} B_{n, m} \rho_{n}^{m}(x)
$$

The scope of evacuation group filling, i.e. the efficiency of the passing process depends on the values of the volume functions $\left(V^{D}, V^{G}\right)$ for the door and bulkhead wall openings, and on the intersection of these openings $\left(S_{C}\right)$, which depends on the direction of effective evacuation and on the total volume of individuals in those openings $\left(V_{n+1}^{m}+V_{n}^{m}\right)$.

\section{CONCLUSIONS}

The term "watertight" with respect to a structure means that it does not allow water to penetrate through it in any direction, under the water head pressure which can occur in undamaged or damaged state $[1,7,14,15]$.

The watertight emergency door meets the requirements of the SOLAS Convention and those of Classification Societies and Institutions. For the time being, the issues of critical states during evacuation of large numbers of individuals through a single opening of the closing bulkhead door have not been analysed.

Based on the analysis and evaluation of the proposed models, the article presents formal description and geometrical and kinematical analysis of critical states of single and sequential door openings during their closing, thus reaching the assumed goal of the research. The scope of the analysis includes models of probable states/relations between openings and individuals, when evacuating the individuals, in critical conditions, through single and multiple door openings.

\section{BIBLIOGRAPHY}

1. Cui H.D. Ji, W.C, Zhang S.K. (2001):Ultimate strength analysis of corrugated bulkheads considering influence of shear force and adjoining structures, Journal of Constructional Steel Research, 57, pp. 525-545.

2. Dymarski Cz., An integrated hydraulic drive system of a novel device for launching lifeboats from large passenger ship. Polish Maritime Research 1 (72) 2012,Vol. 19.

3. Dymarski P., Dymarski Cz., Computational model for simulation of lifeboat motions during its launching from ship in rough seas. Polish Maritime Research 3 (75) 2012,Vol. 19, Gdansk 2012

4. Remontowa Hydraulic Systems Sp. z o.o. Gdansk - structural drawing of the door (in Polish)
5. Ivanov Lyuben D. Deterministic and Probabilistic Calculation of the Strength of Vertically Corrugated Bulkheads in Tankers, Ship Technology Research, Vol. 55, 2008, No. 1, pp. $12-35$

6. Kozak J., Kowalski J.: Problems of Determination of Welding Angular Distortions of T-fillet Joints in Ship Hull Structures// Polish Maritime Research, 2 (86) 2015, Vol. 22, pp.79-85.

7. Lei Huang, Ping Yang, Numerical Analysis on the Ultimate Strength of Corrugated Bulkheads, Chinese Journal of Ship Research, 2011, Vol. 6, No. 3, pp. 28-31,

8. Litwin W.: Influence of main design parameters of ship propeller shaft water-lubricated bearings on their properties; Polish Maritime Research 4(67) 2010, Vol. 17.

9. Malisan Johny1, Jinca M.Y., Parung Herman, Saleng Abrar, Traditional Shipping Transport Safety Case Study: Phinisi Fleet (A study on stability, strength and human resources), International Refereed Journal of Engineering and Science (IRJES) ISSN (Online) 2319-183X, (Print) 2319-1821 Vol. 2, No. 2 (February 2013) Traditional water transport, Safety Case Study: Phinisi Fleet

10. Mosaad M.A., El- Kilani H.S., Ramadan R., and Attia M. : STRENGTH ASSESSMENT OF AGED FORE-END TRANSVERSEBULKHEAD IN BULK CARRIERS, Port Said Engineering Research Journal, Vol. 17, No. 1, pp 175-179.

11. Polish Register of Shipping. Report no. 76/P: Stability, unsinkability and freeboard of passenger ships engaged in domestic navigation (in Polish). Gdansk 2006.

12. Regulation on technical requirements and equipment of inland waterway vessels (in Polish). Government Gazette of 2001, No. 5, Item 43, and No. 100, Item 1085, and of 2002, No. 199, Item 1672.

13. Rudnicki J. Application issues of the semi-markov reliability model, Polish Maritime Research 1(85) 2015, Vol. 22; pp. 55-64. 10.1515/pomr-2015- 000.

14. Yao, X. \& Liu, X. Research on stability design of a barreinforced spherical bulkhead, Journal of Marine Science and Application, Vol.6, No.1, March 2007, pp.1-8.

15. Yu Yan-Yun, Lin Yan, Chen Ming and Li Kai, A new method for ship inner shell optimization based on parametric technique, International Journal of Naval Architecture and Ocean Engineering, Volume 7, Issue 1, January 2015, pp. 142-156. 


\title{
CONTACT WITH THE AUTHOR
}

\author{
Józef Flizikowski \\ e-mail:fliz@utp.edu.pl
}

Wydział Inżynierii Mechanicznej, Uniwersytet Technologiczno-Przyrodniczy im. J. i J. Śniadeckich w Bydgoszczy

S. Kaliskiego 7, 85-796 Bydgoszcz

POLSKA

\section{Weronika Kruszelnicka}

e-mail:weronika.kruszelnicka@gmail.com

Wydział Inżynierii Mechanicznej, Uniwersytet Technologiczno-Przyrodniczy im. J. i J. Śniadeckich w Bydgoszczy

S. Kaliskiego 7, 85-796 Bydgoszcz

PolsKa

\section{Mirosław Michałowski}

e-mail:miroslawmichalowski@rhs.hr.pl

Remontowa Hydraulic Systems Sp. z o.o. Gdańsk ul. Na Ostrowiu 1, 80-958 Gdańsk

Polska

\section{Grzegorz Szala}

e-mail:gszala@utp.edu.pl

Wydział Inżynierii Mechanicznej, Uniwersytet Technologiczno-Przyrodniczy im. J. i J. Śniadeckich w Bydgoszczy

S. Kaliskiego 7, 85-796 Bydgoszcz

POLSKA

\section{Andrzej Tomporowski}

e-mail: a.tomporowski1@wp.pl

Wydział Inżynierii Mechanicznej, Uniwersytet Technologiczno-Przyrodniczy im. J. i J. Śniadeckich w Bydgoszczy

S. Kaliskiego 7, 85-796 Bydgoszcz

POLSKA 